\title{
Expanding the indications for septal myectomy in patients with hypertrophic cardiomyopathy: Results of operation in patients with latent obstruction
}

\author{
Hartzell V. Schaff, MD, Joseph A. Dearani, MD, Steve R. Ommen, MD, Paul Sorajja, MD, and \\ Rick A. Nishimura, MD
}

\begin{abstract}
Objective: Many patients with symptomatic hypertrophic cardiomyopathy have minimal left ventricular outflow tract gradients, and there is uncertainty whether their limitation is due to diastolic dysfunction or labile outflow tract obstruction. The purpose of this study was to characterize the clinical presentation and outcome of septal myectomy in patients with hypertrophic cardiomyopathy and latent obstruction.
\end{abstract}

\begin{abstract}
Methods: Among 749 patients who underwent septal myectomy, 249 had latent obstruction with minimal (0-30 $\mathrm{mm} \mathrm{Hg}$ ) resting gradients preoperatively. All were symptomatic and had more severe left ventricular outflow tract obstruction provoked by Valsalva maneuver or amyl nitrite inhalation during Doppler echocardiography or by stimulation with isoproterenol during catheterization. Clinical characteristics, survival, and functional outcome of these patients were compared with those of 500 patients with more severe resting left ventricular outflow tract obstruction who underwent myectomy during the same period.
\end{abstract}

Results: Compared with those with severe obstruction, more patients with latent obstruction were male (63\% vs $52 \%, P<.003)$, but ages were similar $(53 \pm 14$ years vs $52 \pm 15$ years). Preoperative symptoms and functional limitation were similar in the 2 groups with $86 \%$ and $85 \%$, respectively, having New York Heart Association class III or IV disability. Among patients with latent obstruction, mixed venous oxygen saturation was $61.6 \% \pm$ $19.0 \%$ of predicted compared with $56.8 \% \pm 17.3 \%$ for those with severe resting obstruction $(P<.008)$. Septal thickness was less in patients with latent obstruction $(20 \pm 9 \mathrm{~mm}$ vs $22 \pm 15 \mathrm{~mm}, P<.001)$. Early mortality was $1 \%$ in each group, and survival at 5 and 10 years was $93 \%$ and $87 \%$, respectively, for patients with latent obstruction compared with $93 \%$ and $74 \%$, respectively, for patients with severe resting obstruction preoperatively $(P=.34)$. Self-reported late functional status was similar; 3 to 5 years postoperatively, $81 \%$ of patients with latent obstruction preoperatively were in New York Heart Association class I or II compared with 77\% of patients with severe resting obstruction.

Conclusions: Patients with obstructive hypertrophic cardiomyopathy who have low resting gradients and latent obstruction may have limiting symptoms comparable to those of patients with more severe resting gradients. Septal myectomy should be offered to these patients because survival and symptom relief are excellent, suggesting that dynamic obstruction is the major hemodynamic problem rather than diastolic dysfunction. (J Thorac Cardiovasc Surg 2012;143:303-9)

Standard indications for operation in patients with hypertrophic cardiomyopathy (HCM) include symptoms refractory to medical treatment and severe left ventricular outflow tract (LVOT) obstruction with a resting gradient of more than $30 \mathrm{~mm} \mathrm{Hg}$. Indeed, many experts believe that septal myectomy is the gold standard for treatment of symptomatic patients with obstructive HCM. ${ }^{1,2}$ Previously there

\footnotetext{
From the Divisions of Cardiovascular Surgery and Cardiovascular Diseases, Mayo Clinic, Rochester, Minn.

Disclosures: Authors have nothing to disclose with regard to commercial support.

Read at the 91st Annual Meeting of The American Association for Thoracic Surgery, Philadelphia, Pennsylvania, May 7-11, 2011.

Received for publication May 3, 2011; revisions received Sept 28, 2011; accepted for publication Oct 21, 2011; available ahead of print Dec 12, 2011.

Address for reprints: Hartzell V. Schaff, MD, 200 First Street SW, Rochester, MN

55905 (E-mail: schaff@mayo.edu).

$0022-5223 / \$ 36.00$

Copyright (c) 2012 by The American Association for Thoracic Surgery

doi:10.1016/j.jtcvs.2011.10.059
}

was debate regarding the clinical importance of outflow tract obstruction in patients with HCM, and populationbased studies reported significant obstruction in only $20 \%$ to $44 \%$ of patients with HCM. ${ }^{3}$ Recent reports from Maron and associates ${ }^{4}$ and Elliott and associates ${ }^{5}$ suggest that outflow tract obstruction is a significant risk factor for late death in patients with HCM, and relief of gradients by surgical myectomy may improve survival. ${ }^{6}$

Symptoms, especially exertional dyspnea and fatigue, can be produced by severe diastolic dysfunction in patients with HCM without LVOT obstruction. ${ }^{7}$ Thus, there may be uncertainty in individual patients of the importance of minimal resting gradients in the pathophysiology of limiting symptoms. It is now recognized that in a sizable proportion, patients with minimal LVOT gradients at rest will have larger gradients provocable after exercise, Valsalva maneuver, administration of amyl nitrite, or isoproterenol 


$$
\begin{aligned}
& \text { Abbreviations and Acronyms } \\
& \text { HCM }=\text { hypertrophic cardiomyopathy } \\
& \text { HR }=\text { hazard ratio } \\
& \text { LVOT }=\text { left ventricular outflow tract } \\
& \text { NYHA }=\text { New York Heart Association } \\
& \text { PVC }=\text { premature ventricular contraction } \\
& \text { SAM }=\text { systolic anterior motion }
\end{aligned}
$$

infusion. ${ }^{8,9}$ The dilemma, then, is whether septal reduction for relief of the inducible LVOT obstruction will lead to clinical improvement. To address this question, we have compared outcome (survival and functional status) of patients with HCM and latent LVOT obstruction who underwent septal myectomy with that of patients who had myectomy for relief of severe resting LVOT obstruction.

\section{MATERIALS AND METHODS Patient Selection}

The study was reviewed and approved by the Mayo Clinic Institutional Review Board. The need for individual patient consent was waived because relevant identifiers were not included in the data set, and we excluded patients who declined involvement in clinical research in accordance with Minnesota statutes. From January 4, 1993, to December 31, 2007, 1029 patients with HCM underwent septal myectomy. Cardiologists in our HCM Clinic recorded preoperative evaluations, including assessment of resting LVOT gradients in 749 of these patients who form the study cohort. The remaining 280 patients who underwent operation had preprocedural evaluation by other referring cardiologists and were excluded because of lack of standardized documentation of resting or provocable LVOT gradients. Also, the series does not include patients with the primary diagnosis of valvular aortic stenosis who underwent aortic valve replacement and concomitant septal myectomy for treatment of LVOT obstruction due to secondary septal hypertrophy. ${ }^{10}$

Latent obstruction was defined as LVOT pressure gradient $30 \mathrm{~mm} \mathrm{Hg}$ or less at rest that increased to more than $50 \mathrm{~mm} \mathrm{Hg}$ with provocation. ${ }^{2,9}$ Latent obstruction was often suspected from findings at initial screening evaluation. When there was no resting gradient on prior imaging studies, maneuvers such as Valsalva and stand to squat often provoked a typical systolic murmur signaling dynamic outflow tract obstruction.

All patients had echocardiographic or invasive hemodynamic data documentation of resting and provocable gradients. Medications were not withheld, and echocardiographic studies were performed at baseline according to the recommendations of the American Society of Echocardiography. LVOT gradients were measured with continuous-wave Doppler of the outflow tract from an apical window and calculated using the modified Bernoulli equation (ie, gradient $=4 \mathrm{v}^{2}$, where $\mathrm{v}=$ peak LVOT velocity). Most patients underwent provocation with amyl nitrite or Valsalva maneuver; however, in a small number of patients, gradients were measured after exercise, isoproterenol, dobutamine, or a premature ventricular contraction (PVC). During provocative maneuvers, both 2-dimensional and Doppler data were used to confirm the presence of true outflow tract obstruction. Images were assessed for the presence of systolic anterior motion (SAM) of the mitral valve and absence of complete systolic cavity obliteration, and for hemodynamic measurement, the Doppler signal was required to have the typical late-peaking characteristics of a dynamic obstruction.

Invasive catheterization studies were performed with conscious sedation, and cardiac medications were continued the day of the procedure.
Femoral venous access was used to gain access to the right heart, and left heart pressure measurements were performed via transseptal puncture using $7 \mathrm{~F}$ or $8 \mathrm{~F}$ catheters; the transseptal approach was used to measure left ventricular inflow pressures, which avoids catheter entrapment. A typical spike and dome pattern was required to be present on the aortic pressure trace to ensure dynamic obstruction was present. Simultaneous 2-dimensional echocardiography was always performed during catheterization to ensure that there was associated SAM of the mitral valve during provocation.

Left ventricular pressure measurements were taken in conjunction with cineangiography to avoid catheter entrapment and associated erroneous pressure readings. Central aortic pressure was obtained from retrograde femoral artery access with $6 \mathrm{~F}$ or $7 \mathrm{~F}$ catheters, and LVOT gradient at cardiac catheterization was calculated as peak left ventricular systolic pressure minus the peak central aortic pressure before and after isoproterenol stimulation. ${ }^{11-13}$

\section{Operative Management}

Operations were performed using standard median sternotomy, normothermic cardiopulmonary bypass with single venous cannula, and antegrade cold blood cardioplegia for myocardial protection. Through a low oblique aortotomy, myectomy was performed with a standard number 10 scalpel blade with incision in the septum beginning just to the right of the nadir of the right aortic sinus. Initial incision in the septum was made upward and then leftward over to the anterior leaflet of the mitral valve. Scissors were used to complete excision of this initial portion of myocardium, and the area of septal excision was then deepened and lengthened toward the apex of the heart being certain to excise hypertrophied septum beyond endocardial scar. After trabeculations were excised, the myectomy site was further enlarged with the use of pituitary rongeurs. ${ }^{14}$ No patient had mitral valve replacement as primary treatment of LVOT obstruction. In most patients, associated mitral valve regurgitation was related to SAM and improved by myectomy alone. For patients with associated degenerative mitral valve disease, the valve was replaced in 15 patients and repaired in 95 patients. ${ }^{15}$

To confirm complete relief of the LVOT obstruction, we used intraoperative echocardiography ${ }^{16}$ and routinely measured simultaneous aortic and left ventricular pressure by direct needle puncture before and after myectomy. ${ }^{17}$ If the patient had latent obstruction or the resting LVOT gradient was diminished by effects of anesthesia, provocation was by induction of PVC or isoproterenol administration. PVC was induced by mechanical stimulation of the right ventricle. Isoproterenol challenge was carried out by titrated infusion via a pulmonary catheter to achieve a heart rate greater than 120 beats/min or an LVOT gradient greater than $50 \mathrm{~mm} \mathrm{Hg}$. Aortic and left ventricular pressures were recorded during the same maneuvers after myectomy.

\section{Follow-up and Analysis}

Statistical analyses were performed using SAS software (version 9.1; SAS Institute Inc, Cary, NC). Descriptive statistics for categoric variables are reported as frequency and percentage, and continuous variables are given as mean (standard deviation). Late survival was determined for all patients from medical records, Accurint (www.accurint.com), and surveys. The Kaplan-Meier method was used to estimate late survival, and estimates extend to 12 years. Observed mortality was compared using a log-rank test to expected survival of an age- and sex-matched US general population for the entire follow-up period. Functional status was determined by responses to questionnaires that are sent to postoperative patients $1,3,5,7,10$, and 15 years after operation. This was supplemented by information from medical records when new information was available. In the analysis of functional status, we used the most current follow-up information. For patients who died during follow-up, we used available information on cardiac status 6 months before death. 
TABLE 1. Concomitant cardiac procedures performed in 277 patients who underwent transaortic septal myectomy

\begin{tabular}{lc}
\hline \multicolumn{1}{c}{ Procedure } & No. of patients \\
\hline Mitral valve repair & 95 \\
CABG & 67 \\
Maze procedure & 38 \\
AVR & 32 \\
ASD or PFO repair & 26 \\
Aortic valve repair & 23 \\
Excision of fibroelastoma or other valve tumor & 17 \\
MVR & 15 \\
Tricuspid valve repair & 7 \\
Unbridging of coronary artery & 6 \\
Replacement of ascending aorta & 5 \\
Pericardiectomy & 3 \\
Miscellaneous & 6 \\
\hline
\end{tabular}

Miscellaneous procedures include repair of ascending aortic aneurysm, left atrial thrombectomy, repair of left ventricular aneurysm, right ventricular outflow reconstruction, and carotid endarterectomy. Note that patients may have had more than 1 additional procedure. $C A B G$, Coronary artery bypass graft; $A V R$, aortic valve replacement; $A S D$, atrial septal defect; $P F O$, patent foramen ovale; $M V R$, mitral valve replacement.

\section{RESULTS}

Among all 749 patients, the mean age was $52.3 \pm 14.9$ years, and $56 \%$ were male. Concomitant procedures were performed in 277 patients and are listed in Table 1. The most common associated operations were mitral valve repair and coronary artery bypass grafting, performed in $12.7 \%$ and $8.9 \%$ of patients, respectively. Transaortic septal myectomy was an isolated procedure in $65 \%$ of patients with latent LVOT obstruction and a similar percentage of patients with severe resting gradients. Overall, $85.7 \%$ of patients had severe limitation (New York Heart Association [NYHA] class III or IV) preoperatively, and the most common symptom was exertional dyspnea, present in $73.2 \%$ of patients.

In Table 2, preoperative variables are stratified for patients with $(\mathrm{n}=249)$ and without $(\mathrm{n}=500)$ latent LVOT obstruction. General demographic features of the patients were similar except for a higher proportion of male patients in the group with latent obstruction $(62.7 \%$ vs $52 \%$, $P=.006$ ). Presenting symptoms, extent of preoperative disability, and medication use were similar in the 2 groups; a slightly greater proportion of patients with latent obstruction had preoperative pacemaker/defibrillators in place at the time of operation $(21.7 \%$ vs $15.4 \%, P=.033)$.

Average resting LVOT gradient was $14.0 \pm 9.9 \mathrm{~mm} \mathrm{Hg}$ in patients with latent obstruction compared with $80.9 \pm 33.7$ $\mathrm{mm} \mathrm{Hg}$ for patients with severe resting obstruction preoperatively. As seen in Table 3, patients with latent LVOT obstruction had slightly better exercise capacity preoperatively as judged by mixed venous oxygen saturation compared with patients with severe obstruction. Also, patients with latent LVOT obstruction had less severe mitral valve regurgitation $(37.2 \%>$ grade 2 vs $65.0 \%, P<.001)$.
TABLE 2. Preoperative patient characteristics stratified by preoperative left ventricular outflow tract gradient

\begin{tabular}{|c|c|c|c|}
\hline Covariate & $\begin{array}{c}\leq 30 \mathrm{~mm} \mathrm{Hg} \\
(\mathrm{n}=249)\end{array}$ & $\begin{array}{c}>30 \mathrm{~mm} \mathrm{Hg} \\
(\mathbf{n}=\mathbf{5 0 0})\end{array}$ & $\begin{array}{c}P \\
\text { value }\end{array}$ \\
\hline Male (no.) & $156(62.7 \%)$ & $260(52 \%)$ & .006 \\
\hline Age $(y$, mean $\pm S D)$ & $53.1 \pm 14.4$ & $51.9 \pm 15.1$ & .295 \\
\hline $\begin{array}{l}\text { Body mass index }\left(\mathrm{kg} / \mathrm{m}^{2},\right. \\
\text { mean } \pm \mathrm{SD})\end{array}$ & $30.2 \pm 5.5$ & $30.1 \pm 5.8$ & .737 \\
\hline $\begin{array}{l}\text { Body surface area } \\
\left(\mathrm{m}^{2}, \text { mean } \mathrm{SD}\right)\end{array}$ & $2.0 \pm 0.2$ & $2.0 \pm 0.3$ & .792 \\
\hline NYHA class III or IV (no.) & $215(86.3 \%)$ & $427(85.4 \%)$ & .728 \\
\hline Dyspnea (no.) & $178(72.9 \%)$ & $371(74.9 \%)$ & .205 \\
\hline Angina (no.) & $48(21.3 \%)$ & $131(29.1 \%)$ & .124 \\
\hline Presyncope (no.) & $163(69.3 \%)$ & $290(69.1 \%)$ & .159 \\
\hline Syncope (no.) & $54(22.4 \%)$ & $90(18.9 \%)$ & .373 \\
\hline Preoperative AF & $45(18.1 \%)$ & $82(16.4 \%)$ & .321 \\
\hline \multicolumn{4}{|l|}{ Medications } \\
\hline ß-blocker & $188(75.5 \%)$ & $356(71.2 \%)$ & .214 \\
\hline $\mathrm{Ca}^{++}$-blocker & $111(44.6 \%)$ & $193(38.6 \%)$ & .117 \\
\hline Disopyramide & $29(11.6 \%)$ & $48(59.6 \%)$ & .385 \\
\hline Amiodarone & $18(7.3 \%)$ & $25(5 \%)$ & .217 \\
\hline Previous cardiac surgery (no.) & $33(13.3 \%)$ & $58(11.6 \%)$ & .514 \\
\hline $\begin{array}{l}\text { Permanent pacemaker } \\
\text { or ICD (no.) }\end{array}$ & $54(21.7 \%)$ & $77(15.4 \%)$ & .033 \\
\hline
\end{tabular}

$S D$, Standard deviation; NYHA, New York Heart Association; ICD, implantable cardioverter defibrillator; $A F$, atrial fibrillation.

Left ventricular systolic function was hyperdynamic in both groups, although preoperative ejection fraction was somewhat lower in the group with latent obstruction.

Pertinent outcome measures are presented in Table 4. Durations of cardiopulmonary bypass and aortic crossclamping were shorter in the group with latent LVOT obstruction compared with patients with more severe resting obstruction. Mortality, need for permanent pacing or implantable cardioverter defibrillator, and median length of hospitalization were similar in the 2 groups.

For all patients, 5-year survival was $92.9 \%$ and 10 -year survival was $77 \%$. As seen in Figure 1, there was no significant difference in late survival after septal myectomy of patients with latent LVOT obstruction versus those with severe resting obstruction preoperatively. This was true for all patients and those having isolated septal myectomy (Figure 2). Survival of all patients who had septal myectomy was reduced compared with that of an age- and gender-matched population (10-year survival $77.9 \%$ vs $85.3 \%, P<.001$ ). This difference was due largely to reduced late postoperative survival in patients with high resting LVOT obstruction preoperatively $(P<.001$, Figure 3$)$. Late survival of patients who had septal myectomy for latent LVOT obstruction was almost identical to expected survival (Figure 4).

Significant predictors of overall (early and late) mortality for the entire cohort of patients undergoing myectomy $(\mathrm{n}=749)$ were older age (hazard ratio [HR], 1.04; $P<.001$ ), preoperative atrial fibrillation (HR, 1.84; $P=.011)$, and need for a concomitant cardiac procedure 
TABLE 3. Echocardiographic and hemodynamic characteristics of patients stratified by preoperative left ventricular outflow gradient

\begin{tabular}{|c|c|c|c|}
\hline Covariate & $\leq 30 \mathrm{~mm} \mathrm{Hg}(\mathrm{n}=249)$ & $>30 \mathrm{~mm} \mathrm{Hg}(\mathrm{n}=500)$ & $P$ value \\
\hline Body mass index $\left(\mathrm{kg} / \mathrm{m}^{2}\right.$, mean $)$ & $30.2 \pm 5.5$ & $30.1 \pm 5.8$ & 0.737 \\
\hline Body surface area $\left(\mathrm{m}^{2}\right.$, mean $\left.\pm \mathrm{SD}\right)$ & $2.0 \pm 0.2$ & $2.0 \pm 0.3$ & 0.792 \\
\hline Mixed venous oxygen saturation ( $\%$ predicted, mean $\pm \mathrm{SD}$ ) & $61.6 \pm 19.0$ & $56.8 \pm 17.3$ & 0.008 \\
\hline LVOT gradient $(\mathrm{mm} \mathrm{Hg}$, mean $\pm \mathrm{SD})$ & $14.0 \pm 9.9$ & $80.9 \pm 33.7$ & $<0.001$ \\
\hline Septal thickness $(\mathrm{mm}$, mean $\pm \mathrm{SD})$ & $20.5 \pm 9.0$ & $22.2 \pm 15.5$ & $<0.001$ \\
\hline MR $>$ grade 2 (no.) & $93(37.3 \%)$ & $325(65.0 \%)$ & $<0.001$ \\
\hline Ejection fraction $(\%$, mean $\pm \mathrm{SD})$ & $70.6 \pm 7.9$ & $72.1 \pm 6.6$ & 0.032 \\
\hline
\end{tabular}

$S D$, Standard deviation; $L V O T$, left ventricular outflow tract; $M R$, mitral regurgitation.

(HR, $1.81 ; P=.006)$. In a multivariate Cox regression analysis, only older age was a significant predictor of mortality (HR, 1.04; $P<.001$ ), and when latent obstruction was forced into the model, the resulting HR was $0.76(P=.266)$.

Preoperatively, $86 \%$ of patients were in NYHA class III or IV, and there was no difference in degree of functional impairment comparing patients with latent obstruction with those with more severe resting obstruction. As seen in Figure 5, the extent of functional improvement was similar for the 2 patient groups 5 to 7 years after myectomy, and $79 \%$ of patients in each group were in NYHA class I or II. Beyond 7 years postoperatively, follow-up information was available in 114 patients; $52.2 \%$ of patients with latent obstruction and $61.2 \%$ of patients with severe resting obstruction preoperatively were in NYHA class I or II.

\section{DISCUSSION}

In patients with HCM, the importance of latent obstruction (defined as a left ventricular outflow pressure gradient

TABLE 4. Intraoperative and early postoperative outcomes of patients stratified by preoperative left ventricular outflow gradient

\begin{tabular}{|c|c|c|c|}
\hline Covariate & $\begin{array}{c}\leq 30 \mathrm{~mm} \mathrm{Hg} \\
(\mathrm{n}=249)\end{array}$ & $\begin{array}{c}>30 \mathrm{~mm} \mathrm{Hg} \\
(\mathrm{n}=\mathbf{5 0 0})\end{array}$ & $\begin{array}{c}P \\
\text { value } \\
\end{array}$ \\
\hline \multicolumn{4}{|c|}{$\mathrm{CPB}$ time (min, mean $\pm \mathrm{SD}$ ) } \\
\hline All patients & $50.8 \pm 28.7$ & $55.2 \pm 32.5$ & .058 \\
\hline Isolated myectomy & $39.0 \pm 19.1$ & $43.3 \pm 20.3$ & .011 \\
\hline \multicolumn{4}{|c|}{ Crossclamp time (min, mean \pm SD) } \\
\hline All patients & $35.6 \pm 22.0$ & $40.5 \pm 23.9$ & .002 \\
\hline Isolated myectomy & $27.1 \pm 14.9$ & $32.3 \pm 16.6$ & $<.001$ \\
\hline \multicolumn{4}{|l|}{ Early mortality (no.) } \\
\hline All patients & $2(0.8 \%)$ & $5(1.0 \%)$ & .792 \\
\hline Isolated myectomy & $0(0 \%)$ & $2(0.6 \%)$ & .317 \\
\hline \multicolumn{4}{|c|}{ New pacemaker for bradycardia } \\
\hline All patients & $6(2.4 \%)$ & $21(3.2 \%)$ & .216 \\
\hline Isolated myectomy & $3(1.6 \%)$ & $15(4.6 \%)$ & .128 \\
\hline \multicolumn{4}{|c|}{ ICD for prevention of SCD (no.) } \\
\hline All patients & $15(6.0 \%)$ & $36(7.2 \%)$ & .547 \\
\hline Isolated myectomy & $7(4.3 \%)$ & $25(7.7 \%)$ & .157 \\
\hline \multicolumn{4}{|c|}{ Length of hospitalization (median) } \\
\hline All patients & 6 & 6 & .932 \\
\hline Isolated myectomy & 6 & 6 & .719 \\
\hline
\end{tabular}

$<30 \mathrm{~mm} \mathrm{Hg}$ at rest that increases to $\geq 50 \mathrm{~mm} \mathrm{Hg}$ with provocation) has been recognized only recently. Indeed, most studies evaluating survival and symptom progression of obstructive HCM have stratified patients by the presence or absence of resting gradients of $30 \mathrm{~mm} \mathrm{Hg}$ or more. ${ }^{4,5,18}$ However, it is well known that LVOT gradients in HCM may be highly variable, ${ }^{12}$ and patients with latent obstruction constitute a sizable subgroup. Resting outflow tract gradients of $50 \mathrm{~mm} \mathrm{Hg}$ or more were documented by Maron and colleagues ${ }^{8}$ in $37 \%$ of 320 patients with HCM, and, more important, exercise-induced gradients (mean, $80 \pm 43 \mathrm{~mm} \mathrm{Hg}$ ) were found in an additional 106 patients; thus, as many as $70 \%$ of patients with $\mathrm{HCM}$ who come to clinical evaluation will have significant outflow tract obstruction.

Cardiologists in our HCM Clinic have recognized the importance of latent LVOT obstruction and reported that NYHA class III or IV symptoms are present in approximately $20 \%$ of patients at initial evaluation; in patients with only mild or moderate limitation, symptoms progress in $18 \%$ over a median follow-up of 7.4 years. ${ }^{9}$ Thus, a considerable number of patients with latent LVOT obstruction have serious functional impairment despite medical treatment and may be candidates for septal reduction therapy. Indeed, patients with HCM with latent obstruction constitute $33 \%$ of our recent surgical experience with transaortic septal myectomy.

Relief of LVOT obstruction by transaortic septal myectomy improves symptoms in more than $85 \%$ of patients with severe resting obstruction. ${ }^{19}$ However, diastolic dysfunction is a major pathophysiologic mechanism in HCM; elevation of the left ventricular end-diastolic pressure and increase in left atrial and pulmonary venous pressures may lead to symptoms of effort dyspnea and limited aerobic capacity. As diastolic dysfunction progresses, left ventricular filling becomes more dependent on atrial contraction, and atrial arrhythmias, especially atrial fibrillation, may precipitate acute and profound decrease in cardiac output and worsening of symptoms. In symptomatic patients with minimal resting LVOT gradients, there is often uncertainty regarding the hemodynamic importance of obstruction and the role of septal reduction therapy. This dilemma was highlighted by 1 patient in this series with 


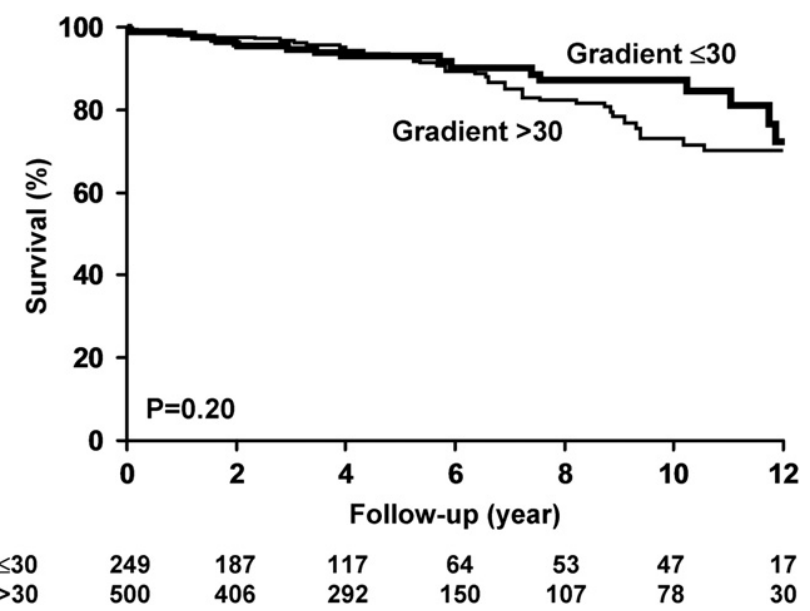

FIGURE 1. Overall survival of all patients after transaortic septal myectomy. Survival was similar for patients with latent obstruction $(\leq 30 \mathrm{~mm}$ $\mathrm{Hg}$ ) preoperatively compared with those with more severe obstruction (>30 mm Hg).

latent obstruction who had been referred for septal myectomy at another institution. The operation was aborted after general anesthesia and prepping and draping for sternotomy because the intraoperative transesophageal echocardiogram showed no obstruction and no SAM of the mitral valve. The patient remained symptomatic with exertional dyspnea until completion of extended septal myectomy at the HCM Clinic.

The present study documents that patients with latent obstruction referred for operation have similar presenting symptoms and functional limitation as patients with more severe resting outflow gradients. The severity of mitral regurgitation at rest was significantly lower in patients with latent obstruction compared with those with high resting gradients, and this is consistent with SAM as a causative

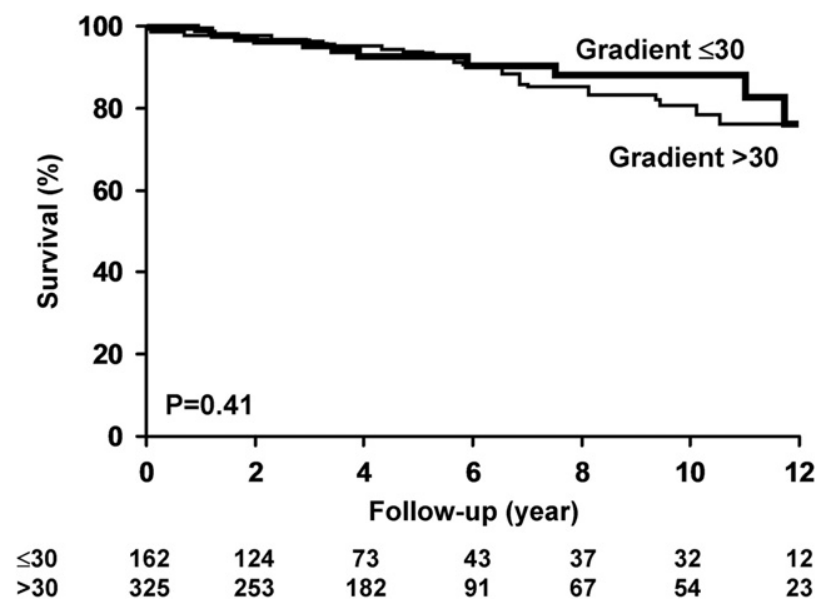

FIGURE 2. Overall survival of patients after isolated transaortic septal myectomy. Survival was similar for patients with latent obstruction $(\leq 30 \mathrm{~mm} \mathrm{Hg}$ ) preoperatively compared with those with more severe obstruction $(>30 \mathrm{~mm} \mathrm{Hg})$.

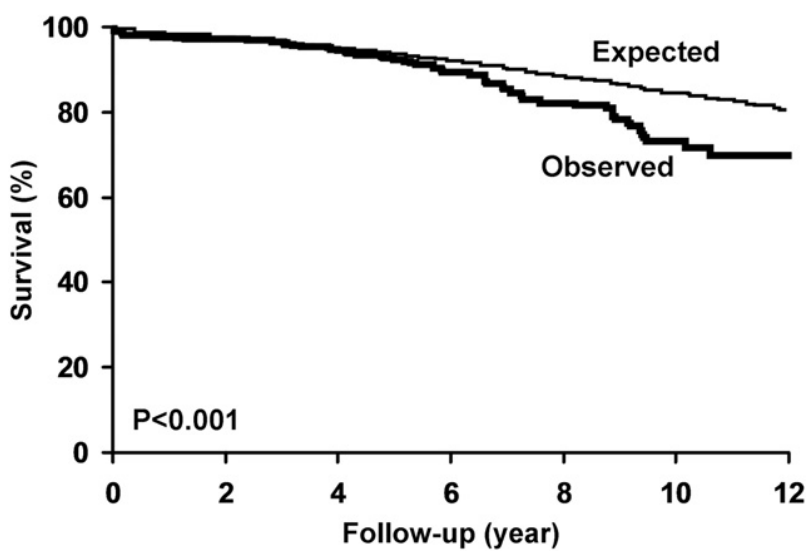

FIGURE 3. Overall survival of patients after transaortic septal myectomy who had high resting gradients preoperatively $(>30 \mathrm{~mm} \mathrm{Hg}$ ). Survival of these patients was reduced in comparison with age- and gender-matched population $(P<.001)$.

mechanism of both LVOT obstruction and mitral regurgitation in most patients. The findings that patients with latent obstruction had less septal hypertrophy and better objective exercise performance suggest that latent obstruction may represent a transition phase from nonobstructive to obstructive HCM. It might be hypothesized that patients with labile LVOT obstruction would be more responsive to medical treatment than patients with severe resting outflow tract gradients. Analysis of this surgical cohort cannot address this, but patients with latent obstruction who underwent septal myectomy had similar medication use as patients with severe resting obstruction.

Of note, our investigation demonstrates that patients with HCM and latent obstruction preoperatively have excellent survival and functional improvement after transaortic myectomy. Operative risk was low for patients with latent obstruction, and subsequent survival was similar to that of patients with severe resting obstruction. Indeed, 10-year

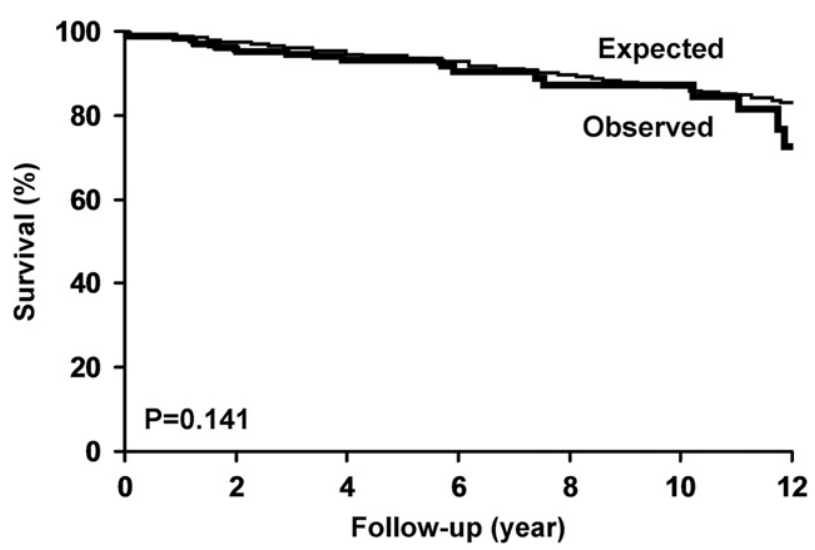

FIGURE 4. Overall survival of patients after transaortic septal myectomy who had latent obstruction preoperatively $(\leq 30 \mathrm{~mm} \mathrm{Hg})$. Survival of these patients was similar to an age- and gender-matched population. 


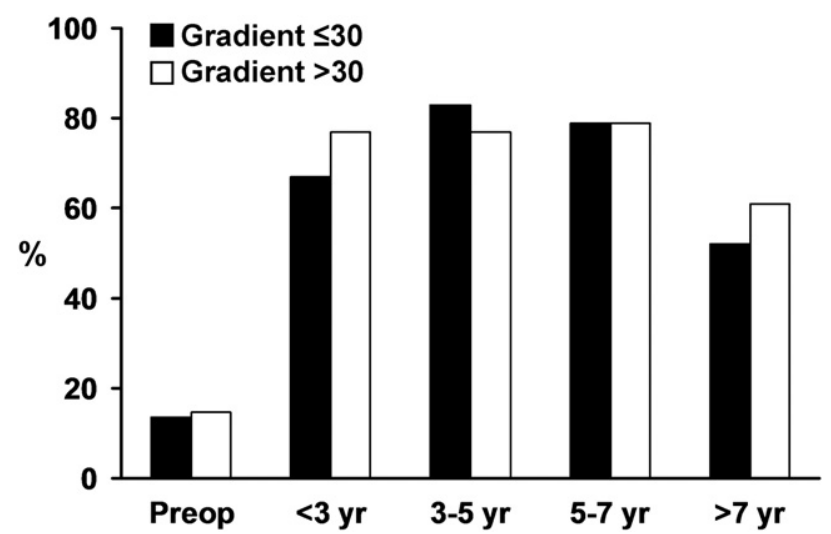

FIGURE 5. Percentages of patients reporting NYHA class I or II status preoperatively and during follow-up after septal myectomy. There is no significant difference in degree of improvement postoperatively comparing patients with latent obstruction $(\leq 30 \mathrm{~mm} \mathrm{Hg})$ preoperatively with those with more severe obstruction $(>30 \mathrm{~mm} \mathrm{Hg}$ ).

survival of patients with latent obstruction preoperatively, including patients with concomitant procedures, was identical to an age-matched group. This finding, along with the comparable improvement in functional status late after operation, suggests that the major contributor to symptoms in patients with latent obstruction is the dynamic outflow gradient rather than severe diastolic dysfunction.

Although septal myectomy is usually performed for relief of symptoms, some consideration should be given to possible improvement in survival after operation. Severe resting LVOT obstruction seems to increase mortality in patients with HCM. ${ }^{4,5}$ Maron and colleagues ${ }^{4}$ reported that risk of death from HCM was increased 2-fold in patients with outflow tract obstruction (a basal gradient of at least $30 \mathrm{~mm}$ $\mathrm{Hg}$ ) compared with patients without obstruction, and risk of progression to NYHA class III or IV or death from heart failure or stroke was increased 4 -fold. ${ }^{4}$ Ommen and colleagues ${ }^{6}$ reported that late survival of patients with HCM who had septal myectomy was similar to survival of patients with HCM without obstruction, and patients with myectomy had improved HCM-related mortality and freedom from sudden cardiac death compared with unoperated patients with HCM with obstruction. More recently, Sorajja and colleagues ${ }^{20}$ found that even in the absence of severe cardiac symptoms, the magnitude of the resting LVOT gradient is directly and independently associated with increasing risk of adverse clinical outcome.

The impact of outflow gradients on late survival is less well documented in patients with latent LVOT obstruction. In the study by Vaglio and colleagues, ${ }^{9}$ patients with HCM with latent obstruction and severe symptoms had a trend toward reduced late survival $(P=.06)$, and better outcome was observed in 82 of these patients who had septal reduction by alcohol septal ablation or myectomy. The favorable impact of septal reduction therapy on mortality is supported by the finding in the present study that late survival of patients with latent obstruction who have myectomy is identical to expected survival of an age and gender-matched population.

Alcohol septal ablation (infarction) is an alternative treatment for patients with drug-refractory symptoms caused by obstructive HCM, and this option is discussed with patients who are candidates for septal reduction. In our experience, alcohol septal ablation improves symptoms in $76 \%$ of patients at 4 years, but the in-hospital complication rate is higher with alcohol ablation than with myectomy, and the question of enhanced propensity for ventricular arrhythmia remains unanswered. ${ }^{21}$ Further, in those patients aged 65 years, symptom relief is better after myectomy, and, for these reasons, we believe surgical myectomy is the preferred technique for septal reduction in patients who are in good general health and have no contraindications for surgery.

\section{CONCLUSIONS}

Patients with obstructive HCM who have low resting gradients and latent obstruction may have limiting symptoms, similar in character and severity to those of patients with more severe resting gradients. Septal myectomy should be offered to these patients because survival and symptom relief are excellent, suggesting that dynamic obstruction is the major hemodynamic problem rather than diastolic dysfunction.

\section{References}

1. Maron BJ, Dearani JA, Ommen SR, Maron MS, Schaff HV, Gersh BJ, et al. The case for surgery in obstructive hypertrophic cardiomyopathy. J Am Coll Cardiol. 2004;44:2044-53.

2. Maron BJ, McKenna WJ, Danielson GK, Kappenberger LJ, Kuhn HJ, Seidman CE, et al. American College of Cardiology/European Society of Cardiology clinical expert consensus document on hypertrophic cardiomyopathy. A report of the American College of Cardiology Foundation Task Force on Clinical Expert Consensus Documents and the European Society of Cardiology Committee for Practice Guidelines. Task Force on Clinical Expert Consensus Documents. American College of Cardiology; Committee for Practice Guidelines. European Society of Cardiology. J Am Coll Cardiol. 2003;42:1687-713.

3. Kofflard MJ, Ten Cate FJ, van der Lee C, van Domburg RT. Hypertrophic cardiomyopathy in a large community-based population: clinical outcome and identification of risk factors for sudden cardiac death and clinical deterioration. J Am Coll Cardiol. 2003;41:987-93.

4. Maron MS, Olivotto I, Betocchi S, Casey SA, Lesser JR, Losi MA, et al. Effect of left ventricular outflow tract obstruction on clinical outcome in hypertrophic cardiomyopathy. N Engl J Med. 2003;348:295-303.

5. Elliott PM, Gimeno JR, Tomé MT, Shah J, Ward D, Thaman R, et al. Left ventricular outflow tract obstruction and sudden death risk in patients with hypertrophic cardiomyopathy. Eur Heart J. 2006;27:1933-41.

6. Ommen SR, Maron BJ, Olivotto I, Maron MS, Cecchi F, Betocchi S, et al. Longterm effects of surgical septal myectomy on survival in patients with obstructive hypertrophic cardiomyopathy. J Am Coll Cardiol. 2005;46:470-6.

7. Abozguia K, Nallur-Shivu G, Phan TT, Ahmed I, Kalra R, Weaver RA, et al. Left ventricular strain and untwist in hypertrophic cardiomyopathy: relation to exercise capacity. Am Heart J. 2010;159:825-32.

8. Maron MS, Olivotto I, Zenovich AG, Link MS, Pandian NG, Kuvin JT, et al. Hypertrophic cardiomyopathy is predominantly a disease of left ventricular outflow tract obstruction. Circulation. 2006;114:2232-9. 
9. Vaglio JC Jr, Ommen SR, Nishimura RA, Tajik AJ, Gersh BJ. Clinical characteristics and outcomes of patients with hypertrophic cardiomyopathy with latent obstruction. Am Heart J. 2008;156:342-7.

10. Kayalar N, Schaff HV, Daly RC, Dearani JA, Park SJ. Concomitant septal myectomy at the time of aortic valve replacement for severe aortic stenosis. Ann Thorac Surg. 2010;89:459-64.

11. Nishimura RA, Schwartz RS, Tajik AJ, Holmes DR Jr. Noninvasive measurement of rate of left ventricular relaxation by Doppler echocardiography. Validation with simultaneous cardiac catheterization. Circulation. 1993;88:146-55.

12. Geske JB, Sorajja P, Ommen SR, Nishimura RA. Left ventricular outflow tract gradient variability in hypertrophic cardiomyopathy. Clin Cardiol. 2009;32: 397-402.

13. Elesber A, Nishimura RA, Rihal CS, Ommen SR, Schaff HV, Holmes DR Jr. Utility of isoproterenol to provoke outflow tract gradients in patients with hypertrophic cardiomyopathy. Am J Cardiol. 2008;101:516-20.

14. Schaff HV. Surgical management of hypertrophic cardiomyopathy, chapter 96. In: Sellke FW, del Nido PJ, Swanson SJ, eds. Surgery of the Chest. 8th ed. Philadelphia: Saunders Elsevier; 2010. p. 1493-506.

15. Wan CK, Dearani JA, Sundt TM 3rd, Ommen SR, Schaff HV. What is the best surgical treatment for obstructive hypertrophic cardiomyopathy and degenerative mitral regurgitation? Ann Thorac Surg. 2009;88:727-31.

16. Ommen SR, Park SH, Click RL, Freeman WK, Schaff HV, Tajik AJ. Impact of intraoperative transesophageal echocardiography in the surgical management of hypertrophic cardiomyopathy. Am J Cardiol. 2002;90:1022-4.

17. Ashikhmina EA, Schaff HV, Ommen SR, Dearani JA, Nishimura RA, Abel MD. Intraoperative direct measurement of left ventricular outflow tract gradients to guide surgical myectomy for hypertrophic cardiomyopathy. J Thorac Cardiovasc Surg. 2011;142:53-9. Epub 2010 Sep 29.

18. Autore $\mathrm{C}$, Bernabò $\mathrm{P}$, Barillà $\mathrm{CS}$, Bruzzi $\mathrm{P}$, Spirito $\mathrm{P}$. The prognostic importance of left ventricular outflow obstruction in hypertrophic cardiomyopathy varies in relation to the severity of symptoms. J Am Coll Cardiol. 2005;45:1076-80.

19. McCully RB, Nishimura RA, Tajik AJ, Schaff HV, Danielson GK. Extent of clinical improvement after surgical treatment of hypertrophic obstructive cardiomyopathy. Circulation. 1996;94:467-71.

20. Sorajja P, Nishimura RA, Gersh BJ, Dearani JA, Hodge DO, Wiste HJ, et al. Outcome of mildly symptomatic or asymptomatic obstructive hypertrophic cardiomyopathy: a long-term follow-up study. J Am Coll Cardiol. 2009;54:234-41.

21. Sorajja P, Valeti U, Nishimura RA, Ommen SR, Rihal CS, Gersh BJ, et al. Outcome of alcohol septal ablation for obstructive hypertrophic cardiomyopathy. Circulation. 2008;118:131-9.

\section{Discussion}

Dr Ralph Damiano (St. Louis, Mo). Dr Schaff, I congratulate you and your coauthors on an important contribution. This is a landmark report that will have a significant impact on the clinical management of patients with symptomatic HCM.

The study stresses the importance of a team approach in the management of HCM and a careful preoperative echocardiographic examination for provocable gradients in these patients. I have several questions for you regarding this excellent contribution.

The first question is, what was the range of provocable gradients, particularly in the latent group? Were patients with higher provocable gradients more likely to have late symptomatic relief?

Dr Schaff. We don't have information on the extent of the provocable gradients other than being able to say it was more than $50 \mathrm{~mm} \mathrm{Hg}$, and the reason is that once the patient achieved that gradient with a Valsalva maneuver, cardiologists did not go further with provocation with Isuprel or exercise that may have increased with gradient further. The provoked gradient, then, is not the maximum provoked gradient.

Dr Damiano. Did you find any preoperative or intraoperative correlates with poor late functional outcome? Particularly when you went back and looked at the patients who had recurrent heart failure, were they the patients who had preoperative echocardiographic criteria for diastolic dysfunction?

Dr Schaff. We don't have any information on diastolic dysfunction, but it makes sense that patients with a larger left ventricular mass have more diastolic dysfunction and might be more likely to have late heart failure.

Dr Damiano. I was intrigued with the large number of patients who underwent concomitant mitral valve surgery. Would you comment on your techniques of mitral valve repair in these patients? Did the presence of preoperative mitral regurgitation or residual postoperative mitral regurgitation correlate with functional improvement?

Dr Schaff. No. The mitral regurgitation for most patients with dynamic outflow tract obstruction will be improved with myectomy alone. Of approximately $10 \%$ of patients who had something done to the mitral valve, most had intrinsic degenerative mitral valve disease as an associated problem. There were a few who had injury to the mitral valve during myectomy. Our approach is to first perform the myectomy, discontinue cardiopulmonary bypass, and then reassess the valve once the obstruction is relieved to see whether there is residual regurgitation. If mitral regurgitation persists, we would resume extracorporeal circulation and repair the valve. I think it is important to assess the valve once the gradient is relieved before making a decision for valve repair.

Dr Damiano. Thank you. Congratulations. 